\title{
The Global Youth Tobacco Survey: 200 I-2002 in Riyadh region, the Kingdom of Saudi Arabia
}

This article was published in the following Dove Press journal:

Substance Abuse and Rehabilitation

I5 November 201।

Number of times this article has been viewed

\section{Abdullah Mohammed \\ Al-Bedah' \\ Naseem Akhtar Qureshi ${ }^{2}$ \\ 'Arabian Center for Tobacco Control, ${ }^{2}$ General Administration for Medical Research and Mental Health and Social Services, Ministry of Health, Riyadh, Saudi Arabia}

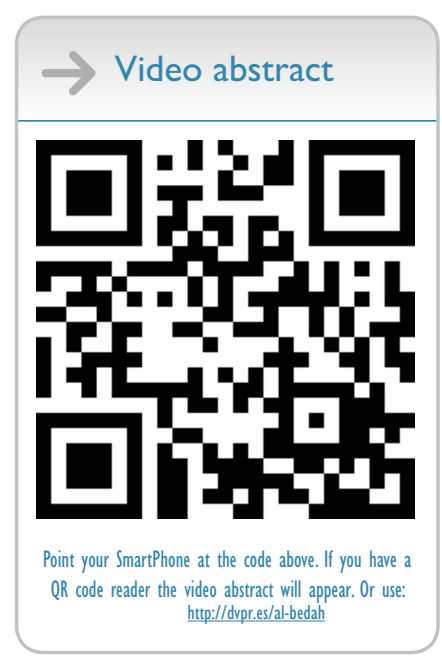

Correspondence: Naseem Akhtar Qureshi General Administration for Medical Research and Mental Health and Social Services, Ministry of Health, Riyadh I I I 76, Saudi Arabia

Tel +966 | 4735038

Fax +966 | 4735039

Email qureshinaseem@live.com
Background: Tobacco use is a major public health problem, and its prevalence is globally increasing, especially among children and adolescents.

Objective: The Global Youth Tobacco Survey aimed to explore the epidemiological trends and risk factors of tobacco smoking among intermediate school boys in Riyadh region of the Kingdom of Saudi Arabia.

Method: A two-stage cluster sample design was used to produce a representative sample of male students from selected schools. The participants $(n=1830)$ self recorded their responses on the Global Youth Tobacco Survey questionnaire.

Results: Lifetime prevalence of cigarette smoking was 35\%, while $13 \%$ of students currently used other tobacco products. About $16 \%$ of students currently smoked at home, and $84 \%$ of students bought cigarettes without any refusal from storekeepers. Thirty-one percent and $39 \%$ of students were exposed to secondhand tobacco smoke inside and outside the house, respectively, which was definitely or probably harmful to health as opined by $87 \%$ of participants, and $74 \%$ voiced to ban smoking from public places. Among current smokers, $69 \%$ intended (without attempt) to quit and $63 \%$ attempted (but failed) to quit during the past year. Almost an equal number of students saw antismoking and prosmoking media messages in the last month, and $28 \%$ of students were offered free cigarettes by a tobacco company representative. In schools, more than $50 \%$ of students were taught about the dangers of cigarette smoking in the last year. Smoking by parents, older brothers, and close friends, watching prosmoking cigarette advertisements, free offer of cigarettes by tobacco company representatives, perception of smoking being not harmful, and continuing smoking which can be easily quit significantly increased the odds of smoking by students.

Conclusion: The common use of tobacco in school populations needs to be addressed by, among other tobacco control measures, a strict ban on cigarette selling to minors and intensive regular tobacco control campaigns involving health and religious messages.

Keywords: tobacco use, secondhand tobacco smoke, environmental tobacco smoke, intermediate school boys, Global Youth Tobacco Survey, Saudi Arabia

\section{Introduction}

Tobacco use, the second major cause of preventable deaths, is the fourth most common risk factor for a variety of diseases. ${ }^{1}$ Smoking is growing rapidly among children, and reportedly 250 million children alive today would die by tobacco use in the near future. Furthermore, half of the children worldwide are exposed to passive smoking at home, ${ }^{2}$ and if both active and passive exposures to children are estimated, the aforementioned figure would be exponential. 
In the Kingdom of Saudi Arabia, a handful of small studies have been conducted to estimate the prevalence of smoking both in community and health settings. ${ }^{3-10}$ The revealed prevalence of current smoking ranged from $17 \%-25.3 \%$ in boys, attributed to desire, stressors, and parental smoking; religion and health issues were the main factors discouraging smoking and the rate of smoking was up to $34.4 \% .^{3-8,10}$ However, large epidemiological surveys among children and adolescents are scanty. In a review, Hamadeh found variable prevalence rates of smoking among males and physicians in the Gulf Cooperation Council (GCC) countries. ${ }^{11}$ The GYTS $^{12}$ in Arab countries revealed that current smoking ranged from $4.1 \%-14.9 \%$ and the current smoking among boys was $4.4 \%-23.1 \%$, the highest in Oman and the lowest in Egypt. In the West, no gender differences exist and current tobacco use ranged from $13.9 \%-45.5 \%{ }^{13}$

Evidently, there is a huge research database on tobacco use in the Western world as compared to the Middle Eastern world. In line with the World Health Organization tobacco survey initiative, a tobacco survey, the first of its kind, was conducted in the Kingdom of Saudi Arabia in the year 2001-2002. Though some results of this survey were published in GCC States report, ${ }^{12}$ this article is quite comprehensive and its findings still have scientific value as to make comparisons with other GYTS conducted subsequently at Arabian Gulf level.

\section{Material and methods GYTS strategy}

The GYTS tracks tobacco use in both genders 13-15 years of age by using a common methodology and a self-administered questionnaire with 56 core and six optional questions. ${ }^{14}$ Both Centers for Disease Control and Prevention and World Health Organization have supported many countries to conduct GYTS to produce comparable epidemiological data globally. ${ }^{14-19}$

\section{Design}

This cross-sectional GYTS was conducted among intermediate school students in Riyadh region; exclusion of other regions was a study limitation. As boys and girls study in separate schools, this survey was restricted to boys only. At the time of inception of this survey, girls' schools were administered by a separate governing body that was refusing the fact that "the girls being smokers," and hence the investigators were not given permission to recruit girls.

\section{Sample}

This survey recruited male students of age 13-15 years from schools with first, second, and third intermediate grades. A two-stage cluster technique was used to produce a representative sample of males. The first-stage consisted of all schools with three intermediate grades, which were selected with probability proportional to school enrolment size. The second-stage consisted of systematic equal probability sampling with randomization of classes from each school that participated in the survey. All intermediate classes in the selected schools were included in the sample. All students in the selected classes were eligible to participate. Notably, exclusion of female students was another study limitation.

\section{Instrument}

The GYTS questionnaire with core questions was used, but with some adaptations to optional questions in order to explore shisha smoking and the antismoking role of religion. The questionnaire was translated to Arabic with back translation into English to check the accuracy of questions. All team members agreed $100 \%$ on all items.

\section{Data collection}

After obtaining permission from the Ministry of Education and school authorities, data was collected from students in 25 sampled schools. The number of participants was 2091, but 1830 students returned completed questionnaires (response rate $=87.5 \%$ ). All participants were informed of study benefits and their responses were anonymous.

\section{Data analysis}

The data was weighted to adjust for sample selection, nonresponse, and poststratification of the sample population relative to the grade and sex distribution in the total population. The weighting factor used a specific formula, and was applied in the present survey. It was also used in GYTS conducted globally. The missing values, expected in self-administered questionnaires were neither imputed nor excluded overall, rather they were excluded from the denominator for individual variable in univariate or pairwise where a bivariate analysis was performed. While adjusting for the complex design and varying responses, standard errors, unweighted frequencies, weighted percentages, 95\% confidence intervals (CI), and odds ratio (OR) were calculated by using Epi Info (v 3.2; Centers for Disease Control and Prevention, Atlanta, GA).

\section{Results}

\section{Demographics}

The participants' age distribution was as follows: $11.4 \%$ were 12 years or younger, $61.8 \%$ were $13-15$ years, and $26.8 \%$ were 16 years or above. Ninety-four percent were nearly 
equally distributed in regular first (35.1\%), second (30.5\%), and third grade $(27.9 \%)$, and $6.5 \%$ were repeaters in any of the three grades. Although this survey targeted students of $13-15$ years of age, some of them were below (11.4\%) and above $(26.8 \%)$ this range.

\section{Lifetime smoking}

When asked if they had ever tried or experimented with cigarette smoking even once in their life, 34.5\% responded yes. The lowest prevalence $(21.8 \%)$ of lifetime smoking was in 14-year-old students. The proportion of students who had ever smoked increased with higher grades and more so for repeaters: $23.0 \%$ of regular first, $34.9 \%$ of regular second, and $44.4 \%$ of regular third grade; $36.9 \%$ repeaters of first, $62.0 \%$ repeaters of second, and $67.2 \%$ repeaters of third grade. The observations on students' age when first attempting smoking were as follows: $14.3 \%$ at age 7 years, $11.8 \%$ at age 8 or 9 years, $17.7 \%$ at age 10 or 11 years, $30.8 \%$ at age 12 or 13 years, $22 \%$ at age 14 or 15 years, and $3.5 \%$ at age 16-18 years. Cumulatively, $43.8 \%$ of those who had ever smoked first tried smoking by age 11 .

\section{Current smoking}

A total of $10.8 \%$ of students had smoked cigarettes on one or more days in the last 30 days. Among those, 60.9\% smoked on 1-9 days, $16.9 \%$ on $10-29$ days, and $22.3 \%$ on all 30 days. Of those who smoked cigarettes daily, $84.1 \%$ smoked ten or less, 5.7\% smoked 11-20, and 10.3\% smoked more than 20 cigarettes (of whom $66.5 \%$ were $\geq 16$ years).

The lowest (2.6\%) and highest (25.9\%) current smoking rate was among 14-year-old and 16-year-old students, respectively. The prevalence of current smoking increased with higher grades and almost doubled in regular students of third grade (14.9\%) as compared to first (6.8\%) and second (7.1\%) grade students. Among the first (23.2\%), second $(36.6 \%)$, and third $(35.3 \%)$ grade repeaters, the prevalence was much higher than students in regular identical classes. When students were asked to categorize themselves, the responses were as follows: $74.2 \%$ never smoked, $14.1 \%$ ex-smokers (6 months or more abstinent from smoking), $6.5 \%$ occasional smokers, $2.5 \%$ chain smokers (smoking most of the time), and $2.8 \%$ daily smokers.

\section{Sources, cost of cigarettes, place of smoking, and craving}

There were two main sources of cigarettes: $40.6 \%$ bought from a store and $20.7 \%$ borrowed from others. Marlboro (Philip Morris USA, Richmond, VA), the model brand, was used by $49.7 \%$ current smokers. More than half (59.3\%) of current smokers reported not buying cigarettes while the remaining had spent $60-180$ or more Saudi riyal in the last 30 days. The two most common places for smoking were public places (46.3\%) and at home (19.2\%). Smoking after a meal, reflecting craving, was reported by $55 \%$ of smokers. Sometimes and always feeling like smoking first thing in the morning was reported by $51.5 \%$ and $2.3 \%$, respectively.

\section{Other tobacco products use}

Reported use of other tobacco products was: $6.8 \%$ used shisha, 5.2\% used moasil, and 1.2\% chewed tobacco. Furthermore, $2.9 \%$ and $1.8 \%$ smoked cigarettes with shisha and moasil. One form of other tobacco products was used by $22.7 \%$ of participants and $13.1 \%$ had used one form of other tobacco products in the last 30 days.

\section{Passive smoking}

Overall, 53.3\% students were exposed to smoking at home or outside during the last 7 days. More than two-thirds of responders $(68.6 \%)$ reported a smoker should get permission from others before smoking, $25.3 \%$ would permit smoking if asked. Compared to $20.7 \%$ of nonsmokers, $71.9 \%$ of current smokers (smoking regularly more than 6 months) would permit smoking.

\section{Future presumptive smoking practice}

When asked if they thought they would be smoking in the next 12 months and the next 5 years, $84.5 \%$ and $84.9 \%$ of students reported negatively to smoking, respectively. If a cigarette was offered by best friends, $14.4 \%$ reported that they would smoke.

\section{Quitting smoking}

Among lifetime smokers, 32.1\% were still smoking. Among quitters, 61.2\% stopped smoking 1-12 months prior and $38.9 \%$ had quit $2-3$ years or more prior. The main reasons for quitting were related to health $(38.8 \%)$, finances $(6.0 \%)$, family $(8.0 \%)$, friends $(2.8 \%)$, Islam $(33.8 \%)$, and other $(10.5 \%)$.

Among current smokers, 69.3\% intended (without attempt) to quit and $62.5 \%$ attempted (but failed) to quit during the past year. In addition, $61.7 \%$ would quit if they intended to, but $38.3 \%$ did not think so. Among lifetime smokers, 26.5\% attempted quitting without success and $17 \%$ received no support to quit whereas $35.5 \%, 23.6 \%$, and $23.8 \%$ received help from antismoking program professionals, friends, and family members, respectively. 
A total of $28.5 \%$ thought it would or would not be definitely difficult to quit once they had started smoking. When asked if they thought smoking was less harmful at their age because they could quit at any time, $68.4 \%$ of students thought absolutely not, $46.4 \%$ did not think so, $17.9 \%$ thought possibly, and $13.7 \%$ thought definitely. When asked if they thought it was safe to smoke for only a year or two as long as they quit after that, $75.6 \%$ of students said definitely not, but $8.7 \%$ thought it likely and $7 \%$ said definitely.

\section{Perceptions and social acceptability of smokers}

Notably, $34.8 \%$ vs $17.8 \%$ participants believed that boys who smoked have more friends, but $7.1 \%$ thought there was no difference from nonsmokers and 40.3\% didn't know. Conversely, $19 \%$ of participants believed that girls who smoked have more friends, but 55.3\% didn't know. Only $11 \%$ of students believed smokers feel more comfortable at social gatherings. Twenty percent of students believed that boys who smoked are more attractive, but $30.8 \%$ believed smoking makes them less attractive. Alternatively, 14\% believed smoking makes girls more attractive. Students' opinion of a person smoking were: disobeying religion (63.7\%), being stupid (21.3\%), lack of confidence $(6.5 \%)$, strong personality (4.8\%), successful (2.4\%), and intelligent $(1.4 \%)$. A similar pattern was revealed in students' opinion of a woman smoking.

\section{Health beliefs and smoking}

The participants' responses to how smoking affects their health were as follows: $36.8 \%$ thought smoking makes you lose weight, $3.7 \%$ thought smoking does not make you lose weight, $10.5 \%$ believed smoking made no difference, and $49 \%$ did not know about such relationships. The majority of students believed that active smoking (89.4\%) and passive smoking $(87.3 \%)$ is harmful to health and $74.2 \%$ of participants favored a ban on smoking in public places.

\section{Social smoking environment}

Both parents of $1.8 \%$, father of $16.3 \%$, and mother of $0.4 \%$ of students smoked. A few students (2.3\%) did not know their parents' smoking status, but $79.2 \%$ reported that their parents did not smoke. Furthermore, brothers of $29 \%$, paternal uncles of $36 \%$, and maternal uncles of $41.8 \%$ of students smoked. Compared to $57.3 \%$ of students who stated that none of their friends smoke, $32.2 \%$ stated that some of their friends smoke and $10.5 \%$ stated that all $(3.7 \%)$ or most $(6.8 \%)$ of their closest friends smoke. Family members discussing with them the harmful effects of smoking was reported by $68.4 \%$ of respondents. Among current smokers, $29.8 \%$ of students thought that their parents knew about their smoking.

\section{Prosmoking campaign}

A total of $14.6 \%$ of students had not been exposed to prosmoking campaigns. Of those who had been exposed, $97 \%$ had seen actors smoking. While watching sports on television, $72 \%$ of students had been exposed to cigarette brand names. About $66.3 \%$ students had seen cigarette advertisements in brochures or flyers. Of the $64.7 \%$ of students who had attended sports events, $67 \%$ had seen cigarette advertisements. Having an item with a cigarette logo on it and being offered free cigarettes by tobacco company representatives was reported by $12.2 \%$ and $27.6 \%$ of students, respectively. Although the sale of cigarettes to minors is prohibited, only $39.5 \%$ were refused sale.

\section{Antismoking campaign}

During the past 30 days, $69.4 \%$ of students were exposed to antismoking messages. During sports or other community events, 85\% had seen antismoking messages. Fifty-four percent of students were taught about dangers of smoking in the current year, but $21.2 \%$ were not sure. Forty-seven percent of students had discussed the reasons of smoking among youth in class, but $22.2 \%$ were not sure. Nearly half $(49.5 \%)$ of students had been taught about the bad effects of smoking, but $21.9 \%$ were not sure. When asked how long ago they had discussed smoking and health as part of a lesson, $24.6 \%$ students said it was never discussed, $13.3 \%$ said it was discussed more than 1 year ago, 20\% said it was discussed last term, and $42 \%$ said it was discussed this term. Both outside the classroom and family milieu, $46.3 \%$ of students said that they had been advised by workers in a sports club or youth association to refrain from smoking during the last year. During the same period, $50.9 \%$ had been advised by a health worker about the bad effects of smoking, while $63 \%$ had been advised by religious leaders.

\section{Potential risk factors of current (past month) smoking}

It was observed that children of parents who smoke were twice as likely to be current smokers (Table 1). The likelihood was four or ten times greater if any of their older brothers or close friends smoke, respectively. Statistically significant associations were observed between current smoking and watching cigarette advertisements on television (Table 2). 
Table I Association between current smoking status and social environment

\begin{tabular}{|c|c|c|c|c|c|c|c|}
\hline \multirow[t]{2}{*}{ Response } & \multirow[t]{2}{*}{ Number of students } & \multicolumn{2}{|c|}{ Smoker } & \multicolumn{2}{|c|}{ Nonsmoker } & \multirow[t]{2}{*}{ OR } & \multirow[t]{2}{*}{$95 \% \mathrm{Cl}$} \\
\hline & & $\mathbf{n}$ & $\%$ & $\mathbf{n}$ & $\%$ & & \\
\hline \multicolumn{8}{|c|}{ Do your parents smoke? } \\
\hline Yes & 312 & 52 & 16.5 & 260 & 83.5 & 2.1 & $1.3-3.4^{*}$ \\
\hline No & 1352 & 122 & 8.8 & 1230 & 91.2 & 1 & \\
\hline \multicolumn{8}{|c|}{ Do any of your older brothers smoke? } \\
\hline Yes & 463 & 74 & 15.6 & 389 & 84.4 & 4.2 & $2.8-6.2^{*}$ \\
\hline No & 902 & 46 & 4.2 & 1009 & 95.8 & I & \\
\hline \multicolumn{8}{|c|}{ Does your uncle smoke? } \\
\hline Yes & 598 & 70 & 11.3 & 528 & 88.7 & 1.3 & $0.7-2.3$ \\
\hline No & 902 & 82 & 9.0 & 820 & 91.0 & I & \\
\hline \multicolumn{8}{|c|}{ Does your maternal uncle smoke? } \\
\hline Yes & 689 & 83 & 11.9 & 606 & 88.1 & $\mathrm{I} .4$ & $0.8-2.4$ \\
\hline No & 830 & 77 & 8.9 & 753 & 91.1 & I & \\
\hline \multicolumn{8}{|c|}{ Do any of your closest friends smoke? } \\
\hline Yes & 705 & 158 & 21.7 & 547 & 78.3 & 9.8 & $6.0-15.8^{*}$ \\
\hline No & 985 & 26 & 2.8 & 959 & 97.2 & I & \\
\hline \multicolumn{8}{|c|}{ Do your parents know that you smoke? } \\
\hline Yes & $|3|$ & 41 & 31.2 & 90 & 68.8 & 1.2 & $0.7-1.6$ \\
\hline No & 309 & 112 & 35.7 & 197 & 64.3 & I & \\
\hline \multicolumn{8}{|c|}{ Has anyone in your family discussed the harmful effects of smoking with you? } \\
\hline Yes & 1148 & $|3|$ & II.I & 1017 & 89.0 & 1.4 & $0.9-2.1$ \\
\hline No & 532 & 44 & 8.1 & 488 & 91.9 & I & \\
\hline
\end{tabular}

Note: *Significant $P \leq 0.05$.

Abbreviations: $\mathrm{Cl}$, confidence interval; $\mathrm{OR}$, odds ratio.

Table 2 Association between current smoking status and exposure to prosmoking media

\begin{tabular}{|c|c|c|c|c|c|c|c|}
\hline \multirow[t]{2}{*}{ Response } & \multirow[t]{2}{*}{ Number of students } & \multicolumn{2}{|c|}{ Smoker } & \multicolumn{2}{|c|}{ Nonsmoker } & \multirow[t]{2}{*}{ OR } & \multirow[t]{2}{*}{$95 \% \mathrm{Cl}$} \\
\hline & & $\mathbf{n}$ & $\%$ & $\mathbf{n}$ & $\%$ & & \\
\hline \multicolumn{8}{|c|}{ When you watch television, videos, or movies, how often do you see actors smoking? } \\
\hline A lot & 1064 & 129 & 11.7 & 935 & 88.3 & 1.0 & $0.5-2.0$ \\
\hline Sometimes & 246 & 27 & 10.9 & 219 & 89.1 & 0.9 & $0.5-1.9$ \\
\hline Never or once & 150 & 18 & 11.8 & 132 & 88.2 & I & \\
\hline \multicolumn{8}{|c|}{ During the past 30 days (last month), when you watched sports events or other programs on television, how often did you see cigarette brand names? } \\
\hline A lot & 526 & 66 & 12.5 & 460 & 87.5 & 2.4 & I.4-4.0* \\
\hline Sometimes & 420 & 77 & 17.7 & 343 & 82.3 & 3.6 & $2.1-6.0 *$ \\
\hline Never or once & 504 & 31 & 5.7 & 473 & 94.3 & I & \\
\hline \multicolumn{8}{|c|}{ How many advertisements for cigarettes have you seen in brochures or flyers in the last 30 days? } \\
\hline A lot & 597 & 87 & 14.2 & 510 & 85.8 & 3.4 & $1.8-6.4^{*}$ \\
\hline A few & 487 & 61 & 11.9 & 426 & 88.6 & 2.7 & $1.6-4.7^{*}$ \\
\hline None & 566 & 26 & 4.7 & 540 & 95.4 & 1 & \\
\hline \multicolumn{8}{|c|}{ How many advertisements for cigarettes have you seen in newspapers or magazines in the last 30 days? } \\
\hline A lot & 601 & 52 & 8.3 & 549 & 91.8 & 1.1 & $0.7-1.7$ \\
\hline A few & 482 & 50 & 10.0 & 432 & 90.0 & 1.3 & $0.8-2.2$ \\
\hline None & 397 & 31 & 7.8 & 366 & 92.5 & I & \\
\hline \multicolumn{8}{|c|}{ When you go to sports or community events, how often do you see an advertisement for cigarettes? } \\
\hline A lot & 438 & 70 & 15.7 & 368 & 84.3 & 3.1 & $1.5-6.3^{*}$ \\
\hline A few & 278 & 31 & 10.2 & 247 & 89.7 & 1.9 & $1.0-3.8^{*}$ \\
\hline None & 441 & 25 & 5.7 & 416 & 94.3 & 1 & \\
\hline \multicolumn{8}{|c|}{ Do you have something with a cigarette brand logo on it? } \\
\hline Yes & 192 & 31 & 15.9 & 161 & 84.1 & 2.0 & I.4-2.8* \\
\hline No & 1436 & 130 & 8.8 & 1306 & 91.2 & I & \\
\hline \multicolumn{8}{|c|}{ Has a cigarette representative ever offered you a free cigarette? } \\
\hline Yes & 474 & 112 & 23.1 & 362 & 76.9 & 5.9 & $3.9-6.7^{*}$ \\
\hline No & 1242 & 62 & 4.9 & 1180 & 95.1 & 1 & \\
\hline
\end{tabular}

Note: *Significant $P \leq 0.05$.

Abbreviations: $\mathrm{Cl}$, confidence interval; $\mathrm{OR}$, odds ratio. 
Notably, current smokers were observed to have a significant association with a free offer of cigarettes by tobacco company representatives. Almost all forms of antismoking media campaigns had no significant association with current smoking status. Ironically, the students who received advice against smoking from any worker in a sports club or youth association were 1.6 times more likely to be current smokers than those who did not receive advice. No statistically significant associations were revealed between the perception of smokers and current smoking status.

In regards to the harmful effect of smoking on health (Table 3), those who believed smoking is not harmful were two times more likely to be current smokers than those who believed it is harmful. The students who thought it was safe to smoke for a year or two as long as they quit later were more likely to smoke than those who do not think so. Likewise, students who thought smoking at their age is less harmful as they can quit smoking at anytime were two times more likely to be current smokers than those who thought otherwise.

Accepting an offer of cigarettes from best friends substantially increased the odds of current smoking (OR: 24.7, 95\% CI: 16.9-36.1). Similarly, smokers who believed that they would be smoking during the next 12 months (OR: 11.2, 95\% CI: 7.8-9.3) and 5 years (OR: 6.8, 95\% CI: 4.8-9.8) from now also showed increased odds of smoking (Table 4).

\section{Discussion}

GYTS has been conducted in boys and girls simultaneously across many countries of the world. ${ }^{14}$ This survey was conducted among school boys only, a study limitation. Therefore, its findings are comparable with smoking pattern among boys in other studies. ${ }^{19}$ The GYTS targets $13-15$ year olds, and in the Saudi education system this age band mostly study in intermediate schools. However, due to lenient policies of school enrolment age and retention of repeaters, almost $37 \%$ of students were outside this age range, which might also impact on the comparison of its results. Age and current smoking status were found to be strongly associated.

Almost one-third of students at intermediate school had tried a cigarette at least once in their life, and another tenth had smoked a cigarette at least once in the last month. These data were consistent with other GYTS in Gulf countries (lifetime smoking [20.9\%-41.5\%] and current smoking [14.3\%-23.1\%]), but inconsistent with other studies outside the Eastern Mediterranean Region. ${ }^{19}$ Although $50 \%$ of students claimed to have smoked less than 6 days in the last month, one-fifth claimed to have smoked daily. This is quite alarming considering $10 \%$ of students smoked more than 20 cigarettes daily, which could lead to the development of disease.

Senior students had a higher prevalence of current smoking compared to students 13-15 years of age, who had collectively the lowest prevalence of current and lifetime smoking. Although this might be due to measurement error, it may indicate a new smoking epidemic among youth that requires a replication study. The age at first cigarette smoking was low, $14.3 \%$ of lifetime smokers had their first cigarette at 7 years or younger and $43 \%$ at 11 years or younger.

Table 3 Miscellaneous beliefs about smoking and current smoking status

\begin{tabular}{|c|c|c|c|c|c|c|c|}
\hline \multirow[t]{2}{*}{ Response } & \multirow[t]{2}{*}{ Number of students } & \multicolumn{2}{|c|}{ Smoker } & \multicolumn{2}{|c|}{ Nonsmoker } & \multirow[t]{2}{*}{ OR } & \multirow[t]{2}{*}{$95 \% \mathrm{Cl}$} \\
\hline & & $\mathbf{n}$ & $\%$ & $\mathbf{n}$ & $\%$ & & \\
\hline \multicolumn{8}{|c|}{ Do you think cigarette smoking is harmful to your health? } \\
\hline Yes & 1589 & 149 & 9.1 & 1440 & 91.0 & $\mathrm{I}$ & \\
\hline No & 189 & 36 & 19.1 & 153 & 80.9 & 2.4 & $1.5-3.8^{*}$ \\
\hline \multicolumn{8}{|c|}{ Do you think smoking cigarettes makes you gain or lose weight? } \\
\hline Gain weight & 67 & 8 & 13.0 & 59 & 87.0 & 0.8 & $0.3-1.9$ \\
\hline No difference & 185 & 32 & 16.4 & 153 & 83.6 & 1 & \\
\hline Lose weight & 654 & 69 & 10.3 & 585 & 89.7 & 0.6 & $0.4-0.9 *$ \\
\hline \multicolumn{8}{|c|}{ Do you think the smoke from other people's cigarettes is harmful to you? } \\
\hline Probably and definitely yes & 1556 & 117 & 7.2 & 1439 & 92.8 & 0.2 & $0.1-0.4^{*}$ \\
\hline Probably and definitely no & 230 & 63 & 27.5 & 167 & 72.5 & $\mathrm{I}$ & \\
\hline \multicolumn{8}{|c|}{ Do you think it is safe to smoke for only a year or two as long as you quit after that? } \\
\hline Probably and definitely yes & 285 & 54 & 18.4 & 231 & 81.6 & 2.2 & $1.5-3.3^{*}$ \\
\hline Probably and definitely no & 1349 & 127 & 9.2 & 1222 & 90.8 & 1 & \\
\hline \multicolumn{8}{|c|}{ Do you believe that smoking cigarettes for a person at your age is less harmful because you can quit smoking at any time? } \\
\hline Possibly yes & 561 & 93 & 15.9 & 468 & 84.1 & 2.3 & $1.4-3.8^{*}$ \\
\hline Absolutely not & 1213 & 92 & 7.5 & 1121 & 92.5 & 1 & \\
\hline
\end{tabular}

Note: *Significant $P \leq 0.05$.

Abbreviations: $\mathrm{Cl}$, confidence interval; $\mathrm{OR}$, odds ratio. 
Table 4 Future presumptive smoking practices and current smoking status

\begin{tabular}{|c|c|c|c|c|c|c|}
\hline \multirow[t]{2}{*}{ Response } & \multicolumn{2}{|c|}{ Smoker } & \multicolumn{2}{|c|}{ Nonsmoker } & \multirow[t]{2}{*}{ OR } & \multirow[t]{2}{*}{$95 \% \mathrm{Cl}$} \\
\hline & $\mathbf{n}$ & $\%$ & $\mathbf{n}$ & $\%$ & & \\
\hline \multicolumn{7}{|c|}{ If one of your best friends offered you a cigarette, would you smoke it? } \\
\hline Probably and definitely yes & 129 & 70.0 & 134 & 8.7 & 24.7 & $16.9-36.1 *$ \\
\hline Probably and definitely no & 54 & 30.0 & 1385 & 91.3 & 1 & \\
\hline \multicolumn{7}{|c|}{ At anytime during the next 12 months, do you think you will smoke a cigarette? } \\
\hline Probably and definitely yes & 80 & 44.5 & 101 & 6.7 & 11.2 & $7.8-9.3^{*}$ \\
\hline Probably and definitely no & 36 & 55.5 & 1410 & 93.3 & 1 & \\
\hline \multicolumn{7}{|c|}{ Do you think you will be smoking cigarettes 5 years from now? } \\
\hline Probably and definitely yes & 70 & 38.0 & $|3|$ & 8.5 & 6.8 & $4.8-9.8^{*}$ \\
\hline Probably and definitely no & 111 & 62.0 & 1419 & 91.5 & I & \\
\hline
\end{tabular}

Note: *Significant $P \leq 0.05$.

Abbreviations: $\mathrm{Cl}$, confidence interval; OR, odds ratio.

This trend further increases the future risk of tobacco-related diseases, which necessitates further expansion of innovative antismoking activities targeting school children. ${ }^{20}$

Tobacco use is a global cause of chronic diseases and mortality. ${ }^{20,21}$ Its addictive potential due to initial experimentation, underappreciated by children, opens windows to other addictions. Over two-thirds of current smokers intend to quit, and a similar proportion attempted to quit but in vain due to the likelihood of nicotine addiction. Quitting was mainly related to Islamic and health beliefs but quitters were largely unaware of supportive sources, (eg, smoking cessation clinics), which include family and social support together with professional help, as well as awareness of campaigns and effective tobacco control programs. ${ }^{22}$ Smoking lifestyle promoted by cigarette manufacturers, further compounded by family and peer role models and easy access to cigarettes, provide vulnerable teenagers a good social milieu to experiment. Thirteen percent of students had used another form of tobacco in the last month and, besides active smoking, more than $50 \%$ were also exposed to passive smoking, all potentially hazardous for growing children.

Students were exposed to both antismoking and prosmoking campaigns simultaneously. The myth of manhood and success linked with smoking had no impact on students, and moreover those believing in this relationship showed no significant association with current smoking. Arguably, prosmoking programs must be countered on equal footing by antismoking strategies. ${ }^{20}$ Furthermore, although the health education messages flashed through multimedia perceived by a wider public were effective delivery techniques, they were not associated with smoking status in this study. Conversely, the health education messages from schools were more effective than media because students have reasonable trust in their teachers. It is worth knowing that direct advertisement of prosmoking in media is prohibited and violators are punished, but indirect advertisement, especially tobacco companies offering free cigarettes in many locations such as restaurants, malls, and cafes, are obvious. Concerned authorities must plug these loopholes in order to curtail devious prosmoking strategies adopted by its promoters.

From the religious perspective, although most of the participants perceived smokers negatively, religious counseling did not show a significant association with current smoking. But a high proportion of students attested to the significance of religion and a major determinant of both quitting and a negative image of adult smokers. Consequently emphasizing religious beliefs in antismoking programs could be an effective way to control smoking in this ultraconservative, religious society.

\section{Conclusion}

In summary, the key findings of this survey were that an increasing number of male students start smoking at a younger age; the revealed prevalence of lifetime smoking among male students was $34.5 \%$; the rate of current smoking ranged from $2.6 \%-25.9 \%$; a number of identified correlates of smoking, especially prosmoking direct and indirect advertisements, were coupled with tobacco use among intermediate school students; both health concerns and religion were important protective factors that appeared to discourage intermediate students not to smoke and to quit smoking; and its findings are fairly consistent with studies conducted in World Health Organization member states. ${ }^{14,19}$ Tobacco control program authorities should include multiple strategies ${ }^{22,23}$ for reducing the growing smoking epidemic among intermediate school students in the Kingdom of Saudi Arabia.

\section{Acknowledgments}

The authors express sincere thanks to administrative staff of boys' schools in Riyadh region and also to World Health 
Organization and Centers for Disease Control and Prevention personnel for their constant support in designing, conducting, analyzing data, and facilitating this survey.

\section{Disclosure}

The authors report no conflicts of interest in this work.

\section{References}

1. World Health Organization. Why tobacco is a public health priority. December 3, 2004. Available from: http://www.who.int/tobacco/ health_priority/en/. Accessed September 29, 2011.

2. World Health Organization. Tobacco and the rights of the child. July 31, 2004. Available from: http://www.who.int/tobacco/resources/ publications/rights_child/en/. Accessed September 29, 2011.

3. Al-Faris EA. Smoking habits of secondary school boys in rural Riyadh. Public Health. 1995;109(1):47-55.

4. Al-Faris EA, Al-Rajhi M, Al-Noor MA. Smoking among females attending a health center in Riyadh, Saudi Arabia. Ann Saudi Med. 1995;15(5):525-528.

5. Saeed AA, Khoja TA, Khan SB. Smoking behaviour and attitudes among adult Saudi nationals in Riyadh City, Saudi Arabia. Tob Control. 1996;5(3):215-219.

6. Jarallah JS, Al-Rubeaan KA, Al-Nuaim AR, Al-Ruhaily AA, Kalantan KA. Prevalence and determinants of smoking in three regions of Saudi Arabia. Tob Control. 1999;8(1):53-56.

7. Siddiqui S, Ogbeide DO, Al-Khalifa I. Smoking in a Saudi community: prevalence, influencing factors, and risk perception. Fam Med. 2001;33(5):367-370.

8. Al-Dawood KM. Pattern of smoking among parents of schoolboys. Saudi Med J. 2000;21(8):735-739.

9. Abolfotouh MA, Abdel Aziz M, Al-Akija W, et al. Smoking habits of King Saud University students in Abha, Saudi Arabia. Ann Saudi Med. 1998;18(3):212-216.

10. Jarallah JS, Bamgboye EA, Al-Ansary LA, Kalantan KA. Predictors of smoking among male junior secondary school students in Riyadh, Saudi Arabia. Tob Control. 1996;5(1):26-29.
11. Hamadeh RR. Smoking in the Gulf Cooperation Council (GCC) countries. Bahrain Med Bull. 1998;20:91-94.

12. Al-Mulla AM, Abdou Helmy S, Al-Lawati J, et al. Prevalence of tobacco use among students aged 13-15 years in Health Ministers' Council/ Gulf Cooperation Council Member States, 2001-2004. J Sch Health. 2008;78(6):337-343.

13. Warren CW, Jones NR, Peruga A, et al. Global Youth Tobacco Surveillance, 2000-2007. Available at: http://www.cdc.gov/mmwr/preview/ mmwrhtml/ss5701a1.htm. Accessed on October 12, 2011.

14. Warren CW, Jones NR, Peruga A, et al. Global youth tobacco surveillance, 2000-2007. MMWR Surveill Summ. 2008;57(1):1-28.

15. Warren CW, Riley L, Asma S, et al. Tobacco use by youth: a surveillance report from the Global Youth Tobacco Survey project. Bull World Health Organ. 2000;78(7):868-876.

16. Global Youth Tobacco Survey Collaborative Group. Tobacco use among youth: a cross country comparison. Tob Control. 2002;11(3):252-270.

17. Erguder T, Cakir B, Aslan D, Warren CW, Jones NR, Asma S. Evaluation of the use of Global Youth Tobacco Survey (GYTS) data for developing evidence-based tobacco control policies in Turkey. BMC Public Health. 2008;8 Suppl 1:S4.

18. Warren CW, Jones NR, Eriksen MP, Asma S; Global Tobacco Surveillance System collaborative group. Patterns of global tobacco use in young people and implications for future chronic disease burden in adults. Lancet. 2006;367(9512):749-753.

19. The Global Youth Tobacco Survey Collaborative Group. Differences in worldwide tobacco use by gender: findings from the Global Youth Tobacco Survey. J Sch Health. 2003;73(6):207-215.

20. Asma S, Warren W, Althomsons S, Wisotzky M, Woollery T, Henson R. Addressing the chronic disease burden with tobacco control programs. Public Health Rep. 2004;119(3):253-262.

21. Marshall L, Schooley M, Ryan H, et al. Youth tobacco surveillance United States, 2001-2002. MMWR Surveill Summ. 2006;55(3):1-56.

22. Farrelly MC, Davis KC, Haviland ML, Messeri P, Healton CG. Evidence of a dose-response relationship between "truth" antismoking ads and youth smoking prevalence. Am J Public Health. 2005;95(3): 425-431.

23. Doubeni CA, Li W, Fouayzi H, Difranza JR. Perceived accessibility as a predictor of youth smoking. Ann Fam Med. 2008;6(4):323-330.
Substance Abuse and Rehabilitation

\section{Publish your work in this journal}

Substance Abuse and Rehabilitation is an international, peer-reviewed, open access journal publishing original research, case reports, editorials, reviews and commentaries on all areas of addiction and substance abuse and options for treatment and rehabilitation. The manuscript management system is completely online and includes a very quick and fair

\section{Dovepress}

peer-review system. Visit http://www.dovepress.com/testimonials.php to read real quotes from published authors. 